\title{
Effect of different endodontic sealers on push-out bond strength of fiber posts
}

\author{
Kiana Ghanadan ${ }^{1}$, Sajjad Ashnagar², Ladan Ranjbar Omrani ${ }^{3}$, Mansooreh Mirzaee ${ }^{3}$ \\ ${ }^{1}$ Hamedan University of Medical Sciences, School of Dentistry, Department of Operative Dentistry, Hamedan, Iran \\ ${ }^{2}$ University of California Los Angeles - UCLA, School of Dentistry, Department of Periodontology, Los Angeles, California, USA \\ ${ }^{3}$ Tehran University of Medical Sciences, School of Dentistry, Department of Operative Dentistry, Tehran, Iran
}

\begin{abstract}
Despite the increasing demand for fiber-reinforced composite (FRC) posts, their bonding to root canals is still subject to debate. Endodontic sealers may affect the bond strength between fiber posts and root canal dentin. Aim: To compare the effects of different sealers on fiber post bond strength. Methods: Sixty teeth were divided into 4 groups according to obturation method: $\mathrm{GI}$, gutta-percha without any sealers; GII, gutta-percha and AH26 resin-based sealer; GIII, RealSeal point and RealSeal resin-based sealer, GIV, Guttaflow. Fiber posts were cemented into root canals. Specimens were sectioned, and the bond strength was measured in the middle area. The failure mode was evaluated. Data were analyzed by one-way ANOVA and post hoc test. Results: The highest bond strength was observed in the control group (2.95 \pm 1.12$)$, and the least was in the Guttaflow group (1.15 \pm 0.78$)$. There was a significant difference between bond strengths of the control and Guttaflow groups and between AH26 and Guttaflow groups $(p<0.05)$. The failure mode was mainly adhesive between dentin and resin cement in all groups. Conclusions: Sealers may have a negative effect on the bond strength of fiber posts to root canal dentin.
\end{abstract}

Keywords: root canal filling materials; dentin; dental pulp; tooth; root canal obturation.

\section{Introduction}

The selection of a proper type of restoration for natural function and esthetic rehabilitation is a major concern in weakened teeth ${ }^{1}$. When the crown is clinically almost destroyed, intraradicullar posts are indicated to secure retention between the prosthetic crown and the remaining tooth structure ${ }^{2-3}$. This retention plays an important role in the durability of the final restoration ${ }^{4}$.

Recent years have seen increased utilization of fiber-reinforced composite (FRC) posts ${ }^{5}$ because of their advantages of desirable esthetics ${ }^{6}$, a modulus of elasticity similar to dentin, stress distribution along a wider surface area on root walls, and minimal risk of vertical root fracture ${ }^{7-8}$.

Received for publication: March 03, 2015 Accepted: June 24, 2015

Correspondence to: Ladan Ranjbar Omrani Department of Operative Dentistry School of Dentistry, Tehran University of Medical Sciences North Kargar St, Amirabad, Tehran, Iran Phone: +989122132110 E-mail:Iadanonrani@yahoo.com

Relating to the limitations in bonding to root canal dentin, numerous studies have been conducted to improve bonding of posts to tooth structures'. Endodontic sealers are among the factors that may have a negative influence on post retention inside the $\mathrm{canal}^{2,10}$.

Endodontic sealers should seal the canal laterally and apically and have acceptable adaptation to the root canal dentin ${ }^{11}$. There is a growing interest in the utilization of resin-based sealers that bond simultaneously to core material and the canal wall, creating a monoblock ${ }^{12}$. These sealers often have the ability to penetrate lateral canals, accessory canals and dentinal tubules ${ }^{11}$. Consequently, it appears that they cannot be removed completely after canal preparation, which 
can adversely affect the bond strength between posts and root canal dentin ${ }^{13}$.

Guttaflow is a new type of siloxine-based sealer that contains two products in one system: gutta-percha particles (less than $30 \mu \mathrm{m}$ ) and polydimethylsiloxine sealer. This injection system has no gutta-percha shrinkage and exhibits only minor expansion during setting because of the cold filling system and absence of heat. Furthermore, removal of this filling material in cases of endodontic re-treatment or preparation of post space would be easier ${ }^{14}$.

This study aimed to assess the effects of two resin-based sealers and Guttaflow on the bond strength of fiber posts. We hypothesized that Guttaflow would have less effect on the bond strength of fiber posts because there is no chemical bond with radicular dentin.

\section{Material and methods}

Sixty human anterior maxillary teeth, extracted because of periodontal problems over a period of 3 months were collected. Informed consent was obtained from patients (ethical approval number 16897). Roots were free of caries, cracks or resorption. Teeth were stored in $0.5 \%$ chloramine $\mathrm{T}$ solution for 1 week and then stored in distilled water. The clinical crowns were sectioned transversely $1 \mathrm{~mm}$ up to the cementoenamel junction, with a low-speed diamond disk with air-water cooling (Isomet 2000; Buehler Ltd, Lake Bluff, IL, USA). Working length of the remaining roots was measured by the direct method, subtracting $1 \mathrm{~mm}$ from the apex by means of a \#10 K file. Biomechanical preparation was performed with rotary instruments of the Mtwo system (VDW $\mathrm{GmbH}$, Munich, Germany). The apical preparation was extended until \#35. The canal was irrigated with $2 \%$ chlorhexidine during instrumentation.

The teeth were randomly divided into 4 experimental groups $(\mathrm{n}=15)$ according to the type of sealer used during the canal filling:

GI: Control group: Teeth were filled with gutta-percha (Coltène/Whaledent, Langenau, Germany) without any sealer, by the lateral condensation technique.

GII: AH26 group: Teeth were filled with AH26 sealer (Dentsply DeTrey GmbH, Konstanz, Germany) and guttapercha by the lateral condensation technique. Root canals were irrigated with $2 \%$ chlorhexidine and dried with absorbent paper points. Sealer was introduced into canals by lentulo spirals.

GIII: RealSeal group: Teeth were filled with RealSeal sealer (SybronEndo, Orange, CA, USA) and RealSeal point. Root canals were irrigated with sodium hypochlorite and dried. Smear layers were eliminated with 17\% EDTA (SmearClear, SybronEndo, Orange, CA, USA). Canals were then irrigated with $2 \%$ chlorhexidine and dried with \# 30 paperpoints (VDW, Munich, Germany). Two pastes of RealSeal were mixed and introduced into canals by lentulo spirals. Filling was completed with RealSeal point by the lateral condensation technique. Teeth were light-cured with a LAVA led unit (Ultradent Products Inc., South Jordan, UT,
USA) $\left(1000 \mathrm{~mW} / \mathrm{cm}^{2}\right)$, for $40 \mathrm{~s}$, from the coronal direction.

GIV: Guttaflow group: Teeth were filled with the Guttaflow system (Coltène/Whaledent, Langenau, Germany). Root canals were irrigated with chlorhexidine and dried with paperpoints. A Guttaflow capsule was then mixed and injected into the canal, and a single gutta-percha cone was inserted into the canal according to the manufacturer's instructions.

After the filling was complete, coronal portions of canals were sealed with temporary cement (Cavit G; 3M ESPE, Seefeld, Germany). The specimens were kept in $100 \%$ humidity for one week at $37{ }^{\circ} \mathrm{C}$. Post space was prepared with Gates-Glidden burs \#2 to \#4 (Dentsply Maillefer) at 10$\mathrm{mm}$ length. The root canals were washed with distilled water, then dried. Fiber glass posts (Angelus, Londrina, PR, Brazil) were cemented by the Panavia F2.0 system, and light-cured for $20 \mathrm{sec}$ with a LAVA LED unit (Ultradent Products Inc.) $\left(1000 \mathrm{~mW} / \mathrm{cm}^{2}\right)$.

Samples were then mounted in transparent acrylic resin and sectioned with a cutting device and diamond-covered disc (Mecatome, Presi, France) in 1-mm slices, by a highspeed sectioning machine. Sections were perpendicular to the long axis of the tooth, and the third and fourth sections were selected. The specimens were fixed in a universal testing machine (Zwick, Ulm, Germany), and the push-out test was done at a cross-head speed of $0.5 \mathrm{~mm} / \mathrm{min}$, from the apical direction. The plunger was selected according to root canal diameter, which was measured by AutoCAD software 2006; the plunger was between 80 and $90 \%$ of canal diameter. It was positioned to touch only the post, without contact with the root canal dentin. The applied force that dislodged the post and cement from the root canal was recorded. The unit of this force was $A=\pi(R+r)\left(h^{2}+(R-r)^{2}\right)^{0.5}$ for conversion into megapascal, in which $\mathrm{R}$ represents the root canal radius in the coronal portion, $\mathrm{r}$ represents the root canal radius in the apical portion, and $\mathrm{h}$ represent the height of specimen slices. Root canal radius was measured with AutoCAD software 2006 .

After the push-out test, the failure mode was evaluated by stereomicroscopy (Nikon type 102, Nikon Corp., Tokyo, Japan) at 40x magnification. Failure classification was cohesive if more than $75 \%$, and adhesive if less than $25 \%$, of the luting resin remained on the tooth surface.

Means and standard deviations were compared by oneway ANOVA and post hoc tests with SPSS software Ver. 16. Statistical significance was set at 0.05 for all analyses.

\section{Results}

Bond strength results of the experimental groups are in Table 1. According to these results, the maximum bond strength was observed in the control group $(2.95 \pm 1.12)$, with the minimum bond strength in the Guttaflow group $(1.15 \pm 0.78)$. AH26 group bond strength data $(2.68 \pm 0.90)$ are closer to the control group than the RealSeal group.

One-way ANOVA of the data showed significant differences between groups $(p<0.05)$. The post hoc analysis 
Table 1: Statistical specifications of bond strength of fiber post in the experimental groups

\begin{tabular}{lccc}
\hline $\begin{array}{l}\text { Experimental } \\
\text { Groups }\end{array}$ & Mean \pm SD & Minimum & Maximum \\
Control & $2.95 \pm 1.12^{\mathrm{a}}$ & 1.23 & 5.24 \\
AH26 & $2.68 \pm 0.90^{\mathrm{a}}$ & 1.38 & 4.64 \\
Realseal & $2.02 \pm 1.27^{\mathrm{a}}$ & 0.29 & 4.58 \\
Guttaflow & $1.15 \pm 0.78^{\mathrm{b}}$ & 0.07 & 2.64 \\
\hline
\end{tabular}

Different letters represent the statistical differences between the groups

of data showed that the control group had the highest bond strength and the Guttaflow group had the lowest bond strength (Figure 1).

Significant differences were observed between the fiber post bond strengths of the control and Guttaflow groups, and between AH26 and Guttaflow groups $(\mathrm{p}<0.05)$. In both comparisons, the bond strength of Guttaflow was less than the other groups.

Failure mode distribution can be observed in Table 2 . Adhesive failure (between cement and dentin) was the most common failure in all groups.

Table 2: Failure mode distribution in the groups (\%)

\begin{tabular}{lccc}
\multicolumn{1}{c}{ Failure Mode } & $\begin{array}{c}\text { Adhesive } \\
\text { Sealer }\end{array}$ & Cohesive & $\begin{array}{c}\text { Adhesive } \\
\text { (cement and dentin) }\end{array}$ \\
AH26 & 54 & 22.7 & 22.7 \\
Control & 58 & 25 & 17 \\
RealSeal & 86.3 & 9 & 4.5 \\
GuttaFlow & 91.6 & 4.5 & 4.5 \\
\hline
\end{tabular}

\section{Discussion}

One of the major problems of fiber posts is dislodgement of the post from the root canal. Posts are placed in spaces prepared by the removal of filling material without encroaching on the apical portion, then bonded to tooth structures with adhesive cements. The success of fiber posts depends directly upon the quality of bonding among the fiber post/cement/root canal dentin ${ }^{15-16}$. Both non-post-related factors, such as type of cement, irrigation solution during root canal preparation and type of sealer, and post-related factors, such as length, diameter, surface and design of the post may affect retention of the fiber post to the root canal walls $^{17-18}$.

Resin-based cements play an important role in the durability of fiber posts. Concerning the limitations of the root canal structure, self-etch resin-based luting cements are utilized to bond fiber posts to overcome problems of wetbonding in total-etch systems ${ }^{16,19}$. The bond would be formed with superficial layers of dentin in self-etch system via smear layer ${ }^{19}$.

Concerning root canal wall modification made by endodontic sealers and canal filling materials, it seems that these materials affect the bond between post and canal walls ${ }^{15-16,20}$.

Resinous sealers have the ability to penetrate lateral canals, accessory canals, and dentinal tubules ${ }^{7}$, and their composition and depth of penetration can have specific effects in reducing the post bond strength ${ }^{16}$. These filled dentinal tubules may be obstructed while post spaces are being prepared, which would interfere with the formation of a hybrid layer of resin cement and dentin.

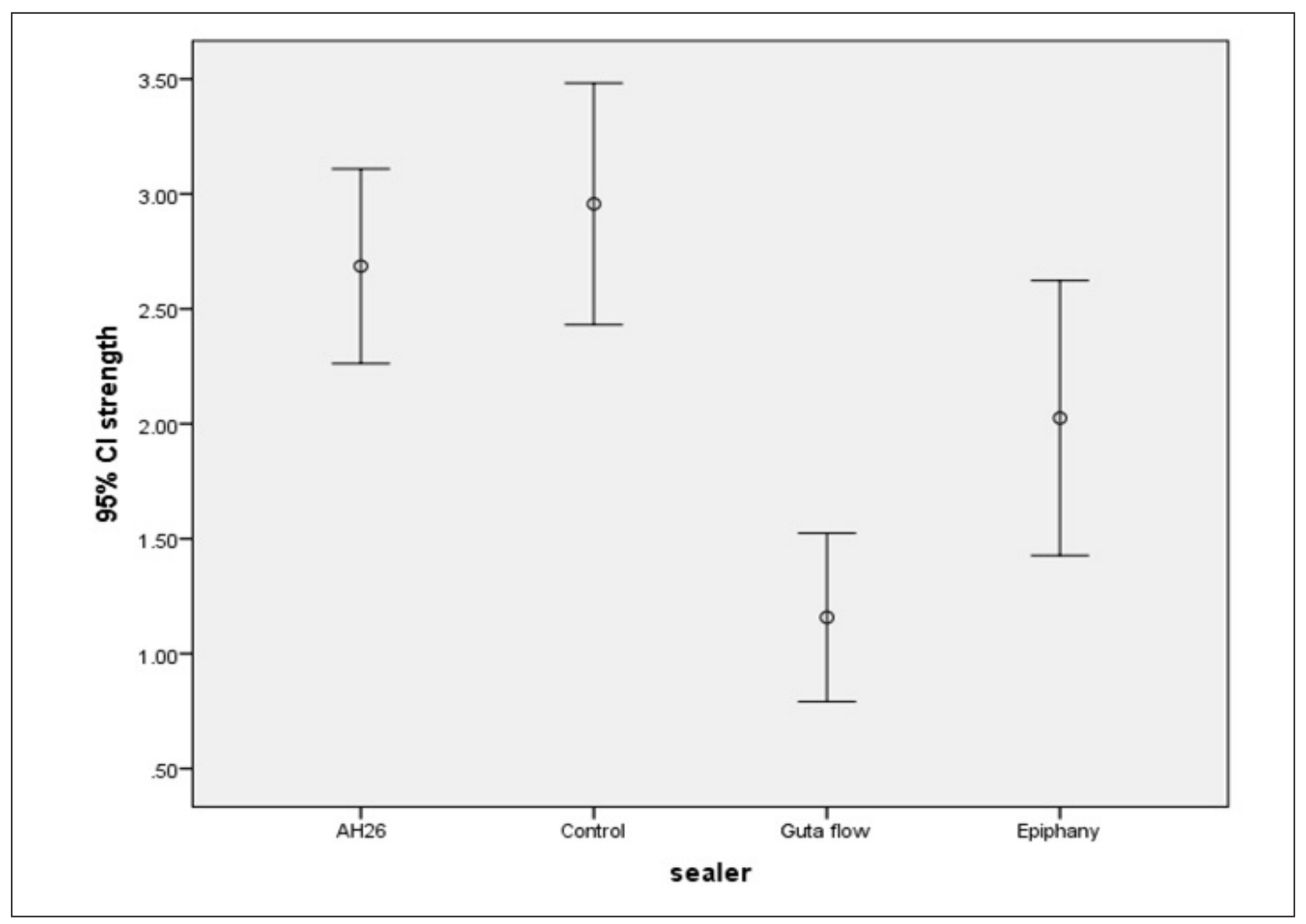

Fig. 1. One way ANOVA analysis for comparison of fiber post bond strength among experimental groups. 
The present study assessed the effect of three types of sealers on bond strength of fiber posts. The effect of each sealer on the bond strength of fiber posts was evaluated by a thin-slice push-out test, which requires 1-mm-thick root disks ${ }^{21}$. Plunger size diameter was chosen according to root canal diameter. This method results in more reliable, reproducible and clinic-like conditions than other tests ${ }^{22}$.This study evaluated the bond strength at the middle third using two serial sections, because other studies reported that the portion of the root canal to have a significant effect on the bond strength of fiber posts ${ }^{23-24}$.

Results indicated that Guttaflow would significantly reduce the fiber post bond strength, in comparison with the control group or the AH26 group. The guttafllow group showed a significant difference from the control group. The highest bond strength was observed in the control group, which lacked any kind of sealer, which agrees with the results of other studies ${ }^{15-16,20}$. This could be explained by the absence of sealers, whereby cement penetration into root dentin was at the highest level ${ }^{7}$.

According to the results of the present study, it may be observed that while the bond strength is decreasing among the sealer groups, the prevalence of adhesive failure mode between dentin and cement is simultaneously rising (Table 2). The lowest bond strength was obtained by the Guttaflow group, with the highest occurrence (91.6\% of samples) of adhesive failure.

The AH26 group showed the highest bond strength among the experimental groups, followed by the RealSeal group. The lack of significant differences confirms the results of some studies ${ }^{7}$, but is in contrast with the results of Demiryurek et al. ${ }^{16}$.This difference may be due to the use of special post drills, which would result in a clean canal surface with high post adaptation, a procedure that would not be used in clinical practice.

Some studies have stated that the penetration of resinbased sealers into dentinal tubules is higher than that of other sealers ${ }^{11,25}$. The degree of penetration of resin-based sealers depends on flow, surface tension, viscosity, chemical compounds, working time, setting time, and solubility of the sealers. AH26 is a highly hydrophilic epoxy resin and may set in humid environments ${ }^{26}$. Some studies have reported that the penetration depth of this sealer is acceptable ${ }^{27}$. The penetration of sealer molecules into dentinal tubules may reduce the bond strength of fiber posts. The present study showed no significant difference between the bond strength of AH26 and the control group, which is in accordance with the findings of Aleisa et al. ${ }^{17}$.

RealSeal SE, is a methacrylate resin-based self-adhesive sealer and contains acidic resin monomers that penetrate into the smear layer and bond to $\mathrm{canal}^{28}$. It seems that due to higher penetration of this sealer into dentinal tubules ${ }^{29}$, less bond strength was observed in comparison with the control group. However, this difference was not statistically significant. Despite the fact that this system is based on the theoretical engagement of the smear layer, recent studies have found that these sealers, especially self-etch sealers, cannot establish a proper bond through the smear layer ${ }^{30}$. Consequently, it is recommended that EDTA be used prior to the application of sealer in root canals, to eliminate the smear layer, reduce microleakage and enhance sealing ability ${ }^{31}$

The fiber post bond strength in the Guttaflow group was the lowest among the experimental groups. It appears that Paramineoil, a composite of Guttaflow, could contaminate root canal walls, reducing the bond strength of cemented posts ${ }^{32}$. Previous studies found that oils and lubricants have a significant impact on bond strength of selfetch systems, reducing over half the original bond strength, which is similar to the results of present study ${ }^{32-33}$. Aggarwal et al. found no significant difference between the fiber post bond strengths of the AH26 and Guttaflow groups compared with the control group. This may be caused by EDTA as a chelating agent prior to post cementation, which would clean any remaining sealer oil from root canal surfaces ${ }^{15}$.

Notwithstanding the fact that we tried to maximize accuracy of experiment and it's comparability to in vivo environment, it is suggested to perform cyclic loading to better simulate oral cavity conditions.

It seems that according to their composition, sealers may have negative effects on the bond strength of fiber posts to root canal dentin. It must be highlighted that, because of negligible reductions in the push-out bond strength of samples, AH26 may be used as a safe sealer, with no concerns about negative effects on the bond strength of fiber posts. It is also suggested to consider future restorative treatment plan when selecting Guttaflow system while performing a root canal therapy.

\section{Acknowledgement}

This research has been supported by the Dental School of Tehran University of Medical Sciences (grant number 16897-69-02-91).

\section{References}

1. Teixeira CS, Pasternak-Junior B, Borges AH, Paulino SM, Sousa-Neto $M D$. Influence of endodontic sealers on the bond strength of carbon fiber posts. J Biomed Mater Res B Appl Biomater. 2008; 84: 430-5.

2. Alfredo E, de Souza ES, Marchesan MA, Paulino SM, Gariba-Silva R, Sousa-Neto MD. Effect of eugenol-based endodontic cement on the adhesion of intraradicular posts. Braz Dent J. 2006; 17: 130-3.

3. Morgano SM. Restoration of pulpless teeth: application of traditional principles in presentand future contexts. J Prosthet Dent. 1996; 75: 375-80.

4. Bateman G, Ricketts DN, Saunders WP. Fibre-based post systems: a review. Br Dent J. 2003; 195: 43-8.

5. Stewardson D. Non-metal post systems. Dent Update. 2001; 28: 326-36.

6. Morgano SM, Rodrigues AH, Sabrosa CE. Restoration of endodontically treated teeth. Dent Clin N Am. 2004; 48: vi, 397-416.

7. Cecchin D, Farina AP, Souza MA, Carlini-Junior B, Ferraz CC. Effect ofroot canal sealers on bond strength of fibreglass posts cemented with self-adhesive resin cements. Int Endod J. 2011; 44: 314-20.

8. Schwartz RS, Robbins JW. Post placement and restoration of endodontically treated teeth: a literature review. J Endod. 2004; 30: 289-301. 
9. Pelegrine RA, De Martin AS, Cunha RS, Pelegrine AA, da Silveira Bueno CE. Influence of chemical irrigants on the tensile bond strength of an adhesive system used to cement glass fiber posts to rootdentin. Oral surg Oral med Oral Pathol Oral Radiol Endod. 2010; 110: e73-6.

10. Menezes MS, Queiroz EC, Campos RE, Martins LR, Soares CJ. Influence of endodontic sealer cement on fibreglass post bond strength to root dentine. Int Endod J. 2008; 41: 476-84.

11. Sabadin N, Bottcher DE, Hoppe CB, Santos RB, Grecca FS. Resinbased sealer penetration into dentinal tubules after the use of $2 \%$ chlorhexidine gel and 17\% EDTA: in vitro study. Braz J Oral Sci 2014; 13: 308-13.

12. Tay FR, Pashley DH. Monoblocks in root canals: a hypothetical or a tangible goal. J Endod. 2007; 33: 391-8.

13. Hassanloo A, Watson $P$, Finer $Y$, Friedman S. Retreatment efficacy of the Epiphany soft resin obturation system. Int Endod J. 2007; 40: 633-43.

14. Só MVR, Saran C, Magro ML, Vier-Pelisser FV, Munhoz M. Efficacy of ProTaper retreatment system in root canals filled with gutta-percha and two endodontic sealers. J Endod. 2008; 34: 1223-5.

15. Aggarwal V, Singla M, MiglaniS, Kohli S. Effect of different root canal obturating materials on push-out bond strength of a fiber dowel. J Prosthodont. 2012; 21: 389-92.

16. Demiryurek EO, Kulunk S, Sarac D, Yuksel G, Bulucu B. Effect of different surface treatments on the push-outbond strength of fiber post to root canal dentin. Oral Surg Oral Med Oral Pathol Oral Radiol Endod. 2009; 108: e74-80.

17. Aleisa K, Alghabban R, Alwazzan K, Morgano SM. Effect of three endodontic sealers on the bond strength of prefabricated fiber posts luted with three resin cements. J Prosthet Dent. 2012; 107: 322-6.

18. Tjan $\mathrm{AH}, \mathrm{Nemetz} \mathrm{H}$. Effect of eugenol-containing endodontic sealer on retention of prefabricated posts luted with adhesive composite resin cement. Quintessence Int. 1992; 23: 839-44.

19. Foxton RM, Nakajima M, Tagami J, Miura H. Adhesion to root canal dentine using one and two-step adhesives with dual-cure composite core materials. J Oral Rehabil. 2005; 32: 97-104.

20. Dimitrouli M, Gunay H, Geurtsen W, Luhrs AK. Push-out strengthof fiber posts depending on the type of root canal filling and resin cement. Clin Oral Investig. 2011; 15: 273-81.

21. Pane ES, Palamara JE, Messer HH. Critical evaluation of the push-out test for root canal filling materials. J Endod. 2013; 39: 669-73.

22. Goracci $C$, Grandini $S$, Bossù $M$, Bertelli $E$, Ferrari $M$. Laboratory assessment of the retentive potential of adhesive posts: a review. J Dent. 2007; 35: 827-35.

23. Soares C, Pereira J, Valdivia A, Novais V, Meneses M. Influence of resin cement and post configuration on bond strength to root dentine. Int End J. 2012; 45: 136-45.

24. Calixto L, Bandéca M, Clavijo V, Andrade M, Vaz L, Campos E. Effect of resin cement system and root region on the push-out bond strength of a translucent fiber post. Oper Dent. 2012; 37: 80-6.

25. Gharib SR, Tordik PA, Imamura GM, Baginski TA, Goodell GG. A confocal laser scanning microscope investigation of the epiphany obturation system. J Endod. 2007; 33: 957-61.

26. Ingle JI, Bakland LK, Baumgartner JC. Root canal filling material. In: Ingle's Endodontics. 6. ed. Hamilton: BC Decker; 2008. p. 1034-43.

27. Nunes VH, Silva RG, Alfredo E, Sousa-Neto MD, Silva-Sousa YT. Adhesion of Epiphany and AH Plus sealers to human root dentin treatedwith different solutions. Braz Dent J. 2008; 19: 46-50.

28. Babb BR, Loushine RJ, Bryan TE, Ames JM, Causey MS, Kim J, et al. Bonding of self-adhesive (self-etching) root canal sealers to radicular dentin. J Endod. 2009; 35: 578-82.

29. Chadha R, TanejaS, Kumar M, Gupta S. An in vitro comparative evaluation of depth of tubular penetration of three resin-based root canal sealers. J Conserv Dent. 2012; 15: 18.

30. Kim YK, Grandini S, Ames JM, Gu LS, Kim SK, Pashley DH, et al. Critical review on methacrylate resin-based root canal sealers. J Endod. 2010; 36: 383-99
31. Kim YK, Mai S, Haycock JR, Kim SK, Loushine RJ, Pashley DH, et al. The self-etching potential of RealSeal versus RealSeal SE. J Endod. 2009; 35: 1264-9.

32. Sugawara T, Kameyama A, Haruyama A, Oishi T, Kukidome N, Takase $Y$, et al. Influence of handpiece maintenance sprays on resin bonding to dentin. Clin Cosmet Investig Dent. 2010; 2: 13.

33. Matos AB, Oliveira DC, Vieira SN, Netto NG, Powers JM. Influence of oil contamination on in vitro bond strength of bonding agents to dental substrates. Am J Dent. 2008; 21: 101-4. 